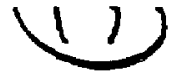

I. 26323

UCID -20228

DE86 010862

FLIBE/He/FS/Be CONCEPT

Ralph Moir

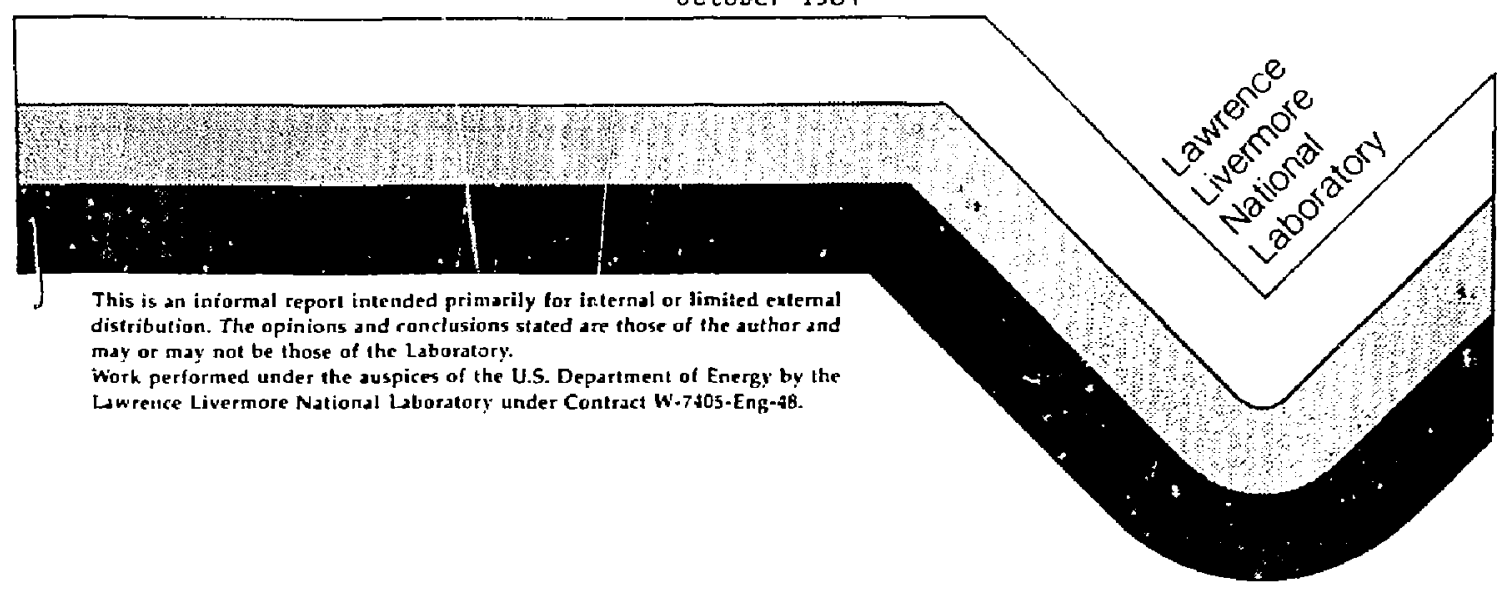




\subsubsection{Flibe/He/FS/De Concept}

The following section discusses a number of special iosues for the flibe design. The salt tubes immersed in th : jed of beryllium bslls muct be spaced so the balls can flow into or out of the tube region with no bridging resulting in flow stoppage. We have conducted flow tests which show that if the balls are no lerger in diameter than one-half of the free space between tube walls, free flow will occur. Since sowe balls way crack or swell and develop ir arfections of shape, we prefer that the ball diameter not exceed one-third at that free apsee. The pebble size is picked to be large enough to avoid excessive pumping power but amall enough to freely flow between the tubes during pebble ch, ngeout and during periodic pebbles movewent to allow for pebble swelling. The nominal values we have chosen are given in Table 8.10-2.

Table $8.10-2$

NOMINAL PEBBLE/PIPE PARAMETERS

\begin{tabular}{ll}
\hline Pipe outside diameter & $1.7 \mathrm{~cm}$ \\
Pipe spacing & $4.7 \mathrm{~cm}$ \\
Pipe wall thickness & $0.5 \mathrm{~mm}$ \\
Pebbl- disutecer & $1.0 \mathrm{~cm}$
\end{tabular}

The tubes are held in place by clips attaching them to perforated grid spacers not shown in the figure.

The tube diameter is large enough so that freeze-up vill not occur and small enough so that the centerline temperature will stay well below the hoiling point $\left(1300^{\circ} \mathrm{C}\right.$ at one atmosphere). These iimits are discussed in the thermal hydraulic section. The tube spacing is selected based on nucleonics. Too large a spacing will give parasitic loss of neutrons in the beryllium and too small a spacing vill displace berylliun and reduce fast neutron multiplication. The tube wall thickness is selected to reduce parasitic absorption in the steel and yet be thick enough to avoid buckling caused by the helium pressure being higher than the salt pressure. Normally, the salt pressire is one atmosphere below the helium pressure, but abnocmally the salt may be depressurized to one atmosphere in which case the tubes vill not buckle. 


\section{Beryllium and Flibe Requirepente}

The salt volune is 92 of the blanket. The scel tube valle are 17 by volume and the otructursl fraction $i s 5 x$ oteel in the beryllium zone. The beryllium pebbles take uf 537 and the Heliud occupies $32 \pi$. In the reflector zone, the beryllium is replaced by SiC which accupies $75 x$ of the volume. The beryllium zone is $20 \mathrm{cr}$ thick and the sic zone is $37 \mathrm{~cm}$ chick, except on the inaide of the Tokamak where it is only $4 \mathrm{~cm}$ thick.

The beryllium zone volume is $0.2 \mathrm{~m}^{3}$ per $0^{2}$ of firat uall area in a Tokamak and $0.23 \mathrm{~m}^{3}$ for the tandem wirror (larger due to the amall first wall radius). The volume of the $37 \mathrm{~cm}$ thick $\mathrm{SiC}$ region is $0.59 \mathrm{~m}^{3}$ in the mircor and $0.37 \mathrm{~m}^{3}$ (essuming the ane coverage on the inside the outside) in the Tokamak. Taking $53 \%$ of the volume being beryllium and a full theoretical density of $1.84 \mathrm{~g} / \mathrm{cm}^{3}$ we get 0.20 tonnes $/ \mathrm{m}^{2}$ for Tokamak and 0.22 tonnes $/ \mathrm{m}^{2}$ for a mirror. The salt volume is $0.033 \mathrm{~m}^{3}$ per $\mathrm{m}^{2}$ in a Tokamak and $0.053 \mathrm{~m}^{3}: \mathrm{n}$ a mirror. For $3000 \mathrm{xW}$ fusion and $5 \mathrm{~kW} / \mathrm{m}^{2}$ neutron, there are $480 \mathrm{~m}^{2}$ of wall area. The salc volume in the blanket for a Tokamak is $16 \mathrm{~m}^{3}$ and in a mirror is $25 \mathrm{~m}^{3}$. The mass of beryllium is 96 tonnes in a Tokamak and 110 tonnes in mirror. There are approximately 100 million pebbles of $1 \mathrm{~cm}$ diameter.

\section{Tube Failure Rate}

Breeder tube failure rate is a concern for this concept. With so many tubes, the question comes up of the failure rate. For the case of a tube nominal spacing of $4.7 \mathrm{~cm}$ on a triangulas array, there vould be $B O, 000$ tubes in the blanket each having an average length of 11 w. If we can tolerate one failure per five years, then the failure rate per tube per hour of operation must be less than $4 \times 10^{-10}$. The helium pressure outside the tube is about I atmosphere higher than the pressure of the molten salt in the tube. Small cracks, at welds, for example, vould result in leakage of helium into the salt and does not constitute a failure. Too large a crack vould result in too large a heliut leak rate and force a shut down and module change but have little overall consequence. An of fset tube break could lead to molten salt contamination of the helium coolant loop. This would require shut down and a clean up procedure to follow. Analysis should be carried out to determine what size of creck is tolerable and then if an acceptable failure rate ( $4 \times 10^{-10}$ per tube per hr) can be achieved. 


\section{Alternute Module End Design}

An alternative module end design to that ohown in Fig. 8.10-1 is presented here. The idea is to allow the end sodules of one sector to support the end modules of the adjacent sector as shown in Fig. 8.10-6. The viewer is looking in the poloidal direction in tokamak or the ezimuthal direction in a tandem mirror. The direction of the lobes is shown here to be poloidal (azimuthal) but could be oriented coroidally (axially) and the idea is equally applicable. Consideration must be given to tolerance nccumulation which can cause overstress of module idewallo. Also, unintentional "cold welding" of walls in contect could occur. This would prevent disassembly without damaging the wodule end-wall in contact with neighboring sector. Both of these unpleasant effects can be overcome by a simple expedient. An aluminutn oxide plate (or several smaller pads) can be mounted on the end walls of modules in adjacent sectors. The aluminum oxide pad thickness can be selected just before final assembly to compensate for colerance build-up in the manufactured condition. Alternatively, a pressurized cushion could be used in conjunction with the aluminum oxide plate to take up the tolerance. The ceramic pads will not weld inside the vacuum. Pad spacing and area must be controlled to minimize any local wall bending stresses in an unsupported area. The space occupied by these thin ceramic pads can be small so that valuable breeding volume is conserved and parasitic neutron capture minimized. clearly, further work is needed on design of the module end support. 


\section{$P=50$ ATMOSPHERES OF HELIUM}

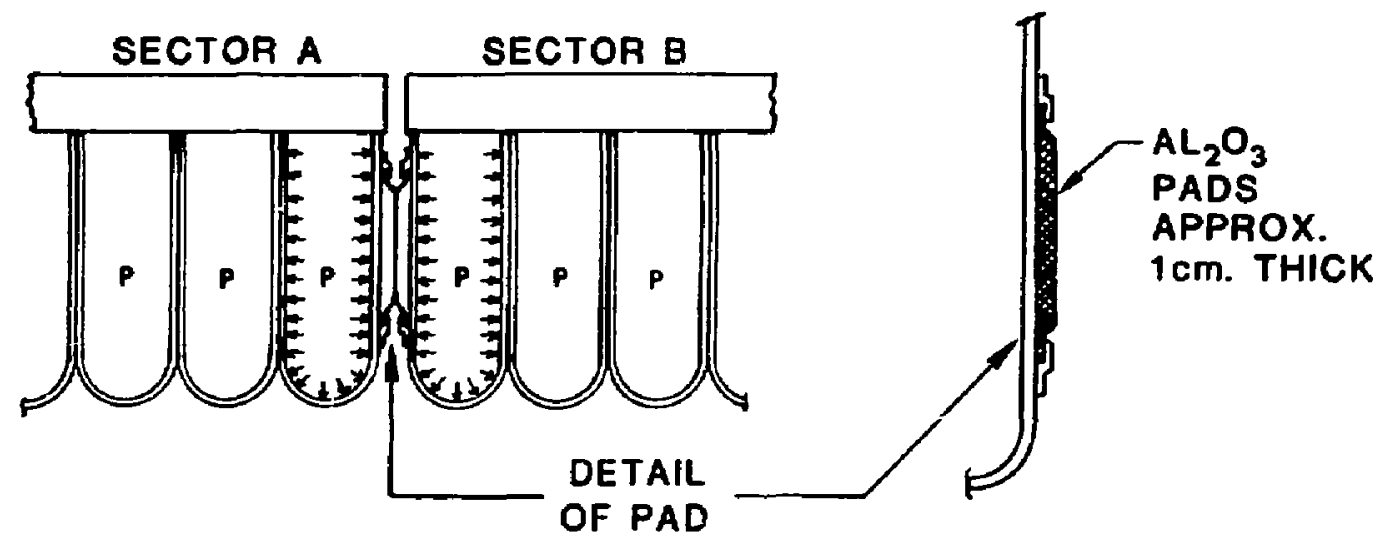

Figure $8 \cdot 10-6$

Alternate module end design. 